\title{
Towards One Health disease surveillance: The Southern African Centre for Infectious Disease Surveillance approach
}

\author{
Authors: \\ Esron D. Karimuribo \\ Kuya Sayalel ${ }^{2,3}$ \\ Eric Beda ${ }^{1}$ \\ Nick Short ${ }^{4}$ \\ Philemon Wambura ${ }^{1}$ \\ Leonard G. Mboera ${ }^{5}$ \\ Lughano J.M. Kusiluka ${ }^{3}$ \\ Mark M. Rweyemamu

\section{Affiliations:} \\ ${ }^{1}$ Southern African Centre \\ for Infectious Disease \\ Surveillance, Morogoro, \\ Tanzania
}

${ }^{2}$ Ngorongoro Conservation Area Authority, Ngorongoro Arusha, Tanzania

${ }^{3}$ The Open University of Tanzania, Dar es Salaam, Tanzania

${ }^{4}$ Royal Veterinary College, London, United Kingdom

${ }^{5}$ National Institute for Medical Research, Dar es Salaam, Tanzania

\section{Correspondence to:}

Esron Karimuribo

Email:

ekarimu@yahoo.co.uk

\section{Postal address:}

PO Box 3297, SUA Morogoro, Tanzania

How to cite this proceeding: Karimuribo, E.D., Sayalel, K., Beda, E., Short, N., Wambura, P., Mboera, L.G. et al., 2012, 'Towards One Health disease surveillance: The Southern African Centre for Infectious Disease Surveillance approach', Onderstepoort Journal of Veterinary Research 79(2), Art. \#454, 7 pages. http:// dx.doi.org/10.4102/ojvr. v79i2.454

Note:

Proceedings of the Conference of the Southern African Centre for Infectious Disease Surveillance 'One Health' held at the National Institute for Communicable Diseases, Johannesburg, July 2011.
Africa has the highest burden of infectious diseases in the world and yet the least capacity for its risk management. It has therefore become increasingly important to search for 'fit-forpurpose' approaches to infectious disease surveillance and thereby targeted disease control. The fact that the majority of human infectious diseases are originally of animal origin means we have to consider One Health $(\mathrm{OH})$ approaches which require inter-sectoral collaboration for custom-made infectious disease surveillance in the endemic settings of Africa. A baseline survey was conducted to assess the current status and performance of human and animal health surveillance systems and subsequently a strategy towards $\mathrm{OH}$ surveillance system was developed. The strategy focused on assessing the combination of participatory epidemiological approaches and the deployment of mobile technologies to enhance the effectiveness of disease alerts and surveillance at the point of occurrence, which often lies in remote areas. We selected three study sites, namely the Ngorongoro, Kagera River basin and Zambezi River basin ecosystems. We have piloted and introduced the next-generation Android mobile phones running the EpiCollect application developed by Imperial College to aid geo-spatial and clinical data capture and transmission of this data from the field to the remote Information Technology (IT) servers at the research hubs for storage, analysis, feedback and reporting. We expect that the combination of participatory epidemiology and technology will significantly improve $\mathrm{OH}$ disease surveillance in southern Africa.

\section{Introduction}

Although there have been some recent advances in the diagnosis and management of human infectious diseases, they still are a significant impact and burden on global economies and public health (Jones et al. 2008). Infectious diseases are responsible for a quarter of all human deaths worldwide (King et al. 2006). Most of these are as a result of emerging infectious diseases (EIDs), defined as infections that have newly appeared in a population or have existed but are rapidly increasing in incidence or geographic range (Morse 1995). There are various drivers for the occurrence of EIDs including socio-economic, environmental and ecological factors. Analysis of origins of EIDs for longer than six decades concluded that over $60 \%$ are zoonotic of which about $72 \%$ originate in wild animals (Jones et al. 1978). It has also been observed that when considering spatial distribution of origins of infectious diseases, the majority are prevalent in and affect developing countries in the tropics, particularly in Africa and South-East Asia.

Effective disease surveillance is required to ensure freedom from EIDs or else timely intervention in order to reduce risks and impact on animal and human populations. Disease surveillance is commonly defined as an ongoing systematic collection, analysis and interpretation of data essential to the planning, implementation and evaluation of disease management practice, closely integrated with the timely dissemination of these data to those who need to know (Mboera, Rumisha \& Kitua 2001; Thacker \& Berkelman 1988). Although the purpose and objectives of disease surveillance may differ between different health sectors, it is generally agreed that surveillance is useful for rapid detection of new and/or foreign diseases, provides evidence of freedom from diseases within a defined geographic area or population, accurately delineates the distribution and occurrence of diseases relevant to disease control and provides evidence required to assess progress and success of disease control or rededication (FAO 2004).

Most developing countries have limited disease surveillance capacity and so need to ensure optimal use of available resources. However, previous studies indicated that both animal and human health sectors are poorly resourced in terms of both clinical and public health service provision (James \& Muchiri 2006; Jones 2011; Karimuribo et al. 2011). Considering that most emerging infectious disease conditions in public health sectors, especially in tropical countries, are of animal (wildlife and domestic) origin (Jones et al. 2008; Wolfe, Dunavan \& Diamond 2007), 
it is important to encourage collaboration between the animal and human health sectors in order to minimise risks associated with such infections. The purpose of this work is to share findings based on our experience in southern Africa focusing on the $\mathrm{OH}$ surveillance strategy developed by the Southern African Centre for Infectious Disease Surveillance (SACIDS).

\section{Materials and methods One Health surveillance}

In this paper, One Health $(\mathrm{OH})$ surveillance is defined as collaborative efforts between the human and animal (wildlife and domestic) health sectors to conduct systematic collection of disease event data, analysis of this data and a timely dissemination of surveillance results to guide interventions aimed to prevent or control disease in human and animal populations.

\section{Study design}

This study involved two phases. Phase 1 involved conducting a baseline survey to assess the performance of current disease surveillance in animal and human health sectors. Lessons learnt from these exercises were used to improve the design of the $\mathrm{OH}$ surveillance system. The second phase involved designing an $\mathrm{OH}$ surveillance system suitable for the southern African region.

\section{Baseline study on assessment of surveillance systems}

A rapid situation analysis was carried out in May 2010 to understand the structure and requirement of surveillance systems in the animal and human health sectors in Tanzania. This was followed by assessing the performance of the disease surveillance systems in the two health sectors by visiting animal and human health facilities in Ngorongoro district, carried out in November 2010. During field visits, individuals responsible for detection and reporting of disease events were interviewed using a structured questionnaire. A total number of 14 wards of Ngorongoro district were visited where all resident ward livestock field officers (LFO) were interviewed. The study also collected data from 13 health facilities, representing approximately $62 \%$ of all health facilities in Ngorongoro district. The exclusion of an individual health facility was based on lack of access to key personnel or disease surveillance records during the field visit. Respondents were asked to specify frequency of collection and submission of disease surveillance reports, diseases reported and constraints and challenges faced during disease surveillance in animal and human health sectors. Field data collection was complemented by visiting the District Veterinary Office (DVO) and District Medical Office (DMO) at the Ngorongoro District Council headquarters where disease surveillance reports submitted for the period from 2005 to 2010 were retrieved and analysed.

The assessment of disease surveillance in both animal and human health sectors was based on measuring the completeness and accuracy of surveillance reports focusing on a period of five years (2005-2010) before the study. Other factors that might have influenced the timely submission of disease reports such as the distance from a health facility to the district headquarters were also recorded.

\section{Design of Southern African Centre for Infectious Disease Surveillance One Health surveillance strategy in southern Africa}

A participatory approach was used at an initial project inception workshop organised to agree on study sites and surveillance approaches. During the workshop, held in January 2010, it was agreed to develop and pilot $\mathrm{OH}$ surveillance in three ecosystems namely Ngorongoro, Kagera River basin and Zambezi River basin. The workshop recommended initial pilot activities to be carried out in one ecosystem (Ngorongoro) and then up-scaling the approach to the other two project sites.

Implementation of the project activities in Ngorongoro ecosystems required a collaborative approach coordinated by SACIDS and National Centre for Infectious Disease Surveillance (NatCIDS). Other key collaborators in the development of the $\mathrm{OH}$ surveillance strategy in Tanzania were: the Ministry of Health and Social Welfare (Epidemiology unit), the Ministry of Livestock and Fisheries Development (Epidemiology section) and two academic institutions responsible for veterinary (Sokoine University of Agriculture) and medical (Muhimbili University of Health and Allied Sciences) training in the country. The project also partnered with collaborators from UK, namely the Royal Veterinary College (RVC) and Imperial College London, who assisted in sharing with the southern colleagues their experiences in infectious disease surveillance and the use of appropriate technologies and tools to support $\mathrm{OH}$ disease surveillance. Recommendations of the UK Foresight report on infectious diseases (Brownlie et al. 2006) were also considered whilst devising $\mathrm{OH}$ surveillance strategy in southern Africa.

\section{Study sites}

The current project on $\mathrm{OH}$ disease surveillance adopted three study sites namely Ngorongoro, Kagera River basin and Zambezi River basin ecosystems. The first ecosystem represents an area of maximum human-wildlife-domestic animal interactions. The ecosystem is located in a remote area in the Arusha region which borders Kenya in the north and the Tanzanian Serengeti ecosystem in the west. The ecosystem is predominantly inhabited by the Maasai pastoral communities who keep cattle, goats and sheep and are in close proximity with wild animals in the wildlife protected areas of Ngorongoro Conservation Area (NCA). The other two sites (Kagera River basin and Zambezi River basins) represent cross-border ecosystems where $\mathrm{OH}$ surveillance could be potentially effective in diagnosing and managing infectious diseases across borders. Kagera River basin is an ecosystem located in the Great Lake Region of eastern Africa which links Uganda, Rwanda, Burundi and Tanzania. The ecosystem has a relatively high incidence of communicable 
diseases with cross-border spread and is considered to be a high risk potential entry-point for haemorrhagic fever (especially Ebola and Marburg) which occur in the Democratic Republic of Congo (DRC). Zambezi River basin is located in the southern Africa and is the fourth largest basin in Africa after the Congo, Nile and Niger River basins. The Zambezi River has its source in Western Province of Zambia and flows through eastern Angola, Namibia (Eastern Caprivi strip), northern Botswana and through Victoria falls (shared between Zambia and Zimbabwe) before entering Lake Kariba. The project site focused on two districts of Zambia (Kazungula and Sesheke) which share international borders with Zimbabwe, Botswana, Namibia and Angola in the Zambezi River basin ecosystem.

\section{Data analysis}

Data collected during baseline study on assessment of the performance of disease surveillance systems were summarised and where applicable, descriptive statistics computed. Data trends by ward and health facilities were demonstrated using graphical presentation of the results. The names of health facilities were coded to ensure a blind contribution in disease reporting to comply with ethical clearance conditions.

\section{Results}

\section{Baseline study on the performance of surveillance system in the animal and human health sector in Tanzania}

\section{Disease surveillance structure}

The surveillance structure between the animal and human health sectors in Tanzania was found to be similar (Table 1). The initial detection of disease events in both health sectors starts in the communities where sick individuals are detected by community-based reporters. The current systems use official cadres who are the LFOs (in animal health sectors) and the health facility in-charge or Integrated Disease Surveillance and Response (IDSR) focal person (in human health sectors) to prepare and submit disease surveillance reports to the higher levels. The central coordinating level for disease surveillance and response is at the district level (DVO and DMO). The two offices are responsible for transmitting reports to higher authorities through the intermediate (zonal VICs and RMO) or sometimes directly to the central level in the ministry responsible for animal health and human health, respectively. The similarities in surveillance structures of the two health sectors offer opportunities for increased collaborations between veterinary and medical professionals with regards to disease surveillance and response.

With respect to frequency of reporting, the animal health sector demands submission of disease reports on a monthly basis using field and abattoir surveillance reports. In the case of notifiable diseases, the officials are required to report disease events immediately. Under the IDSR system, officials are required to report diseases under surveillance on weekly (epidemic-prone conditions) and monthly (epidemic-prone, diseases of public health importance and those targeted for eradication) basis.

\section{Performance of surveillance systems}

A total number of 13 human health facilities (dispensaries, health centres and hospitals) were visited and participated in this study. The facilities were located between $1 \mathrm{~km}$ and $237 \mathrm{~km}$ from the Ngorongoro District Council headquarters (Table 2). More than $69 \%$ of these facilities are owned by the local government authority, the Ngorongoro District Council. It was also found that organisations such as the Roman Catholic and the Evangelical Lutheran Churches of Tanzania run some health facilities that, in addition to offering health services, are involved in the capture and reporting of disease events in the study area.

The performance of disease surveillance in animal and human health sectors, defined by the number of surveillance reports received every month is shown in Figure 1. Overall, the reporting was better in the human health sector than in the animal health sector. There were some years such as 2008 and 2009 when the DVO did not receive a single disease report. Similarly the DMO did not receive monthly reports from human health facilities throughout 2005. Generally, some wards and health facilities performed better in submitting disease surveillance reports compared to others (Figures 2a and Figure 2b). It was clear that those wards and facilities close to the District Council headquarters submitted reports more regularly than the distant wards and facilities.

\section{One Health surveillance strategy in southern Africa}

The $\mathrm{OH}$ surveillance strategy was developed as a result of a participatory and consultative process summarised in Table 3.

TABLE 1: Similarities between disease surveillance structure in animal and human health sectors in Tanzania.

\begin{tabular}{|c|c|c|}
\hline \multirow[t]{2}{*}{ Level } & \multicolumn{2}{|r|}{ Sector } \\
\hline & Animal health & Human health \\
\hline Peripheral (Community) & Farmers and community-based animal health workers & Community based health workers or community-owned resource persons \\
\hline Peripheral (Village and wards) & Livestock Field Officers and Ward Agriculture Extension Officers & $\begin{array}{l}\text { In-charge or focal points for IDSR at health facilities (dispensaries, health } \\
\text { centres or hospitals) }\end{array}$ \\
\hline Intermediate (District) & $\begin{array}{l}\text { District Veterinary Officers or District Agriculture and Livestock } \\
\text { Development Officers }\end{array}$ & District Medical Officers \\
\hline Intermediate (Region or zone) & Zonal veterinary investigation centres & Regional Medical Officers \\
\hline Regional or international & Regional or international bodies (e.g. AU/IBAR, SADC, EAC, OIE) & Regional or international bodies (e.g. EAC, WHO) \\
\hline
\end{tabular}

IDSR, Integrated Diseases Surveillance and Response strategy. 
Before project implementation, applications were submitted to the appropriate bodies responsible for ethical clearance in the National Institute for Medical Research (NIMR) and the Tanzania Wildlife Research Institute (TAWIRI). Holding an inception workshop for key stakeholders interested in $\mathrm{OH}$ surveillance was helpful in selecting study sites as well as identification of appropriate mobile technologies and tools to assist surveillance. The subsequent meetings of the NatCIDS and the Joint Technical Committee (JTC) in August and September 2010 respectively, defined the $\mathrm{OH}$ surveillance strategy to be adopted in Ngorongoro and later in two other project sites. The meetings agreed that the strategy should consist of two complementing systems namely:

- Community-based Active Surveillance (CAS) system which was designed to actively capture disease events in animal and human populations using simple case definitions of symptoms and syndromes occurring in communities. It was also agreed the CAS system would use community-based health reporters who would actively screen for the occurrence of disease events in human, wildlife and domestic animal populations. Data on these events would be recorded and transmitted through Android mobile phones using the Epicollect data capture application in near to real time.

- District-based Passive Surveillance (DPS) system uses existing surveillance strategies in animal and human (IDSR) health sectors with enhanced performance through application of mobile technologies in transmission of near to real time data in the two health sectors.

Collaborating with other institutions in the United Kingdom (Royal Veterinary College and Imperial College London) as well as those in South-East Asia (BIOPHICS, Ministry of Public Health Thailand, MBDS and InsTEDD, Cambodia) assisted in the improvement of the $\mathrm{OH}$ surveillance system developed by SACIDS. The two systems (CAS and DPS) are linked together at the data analysis point. Data collected through CAS and DPS systems from pilot sites located in Tanzania are stored centrally on a server located at SACIDS headquarters. Southern African Centre for Infectious Disease Surveillance acts as a custodian and stores data on behalf of the Ministry of Livestock and Fisheries Development and the Ministry of Health and Social Welfare who own the data. At SACIDS, data are analysed and summarised as reports that are shared with the two ministries and field-based disease management units at district headquarters. A similar model is proposed for dealing with handling data collected in Zambezi River basin when data storage and analysis is expected to be the role of the University of Zambia Veterinary School (UNZA Vet) on behalf of respective ministries responsible for animal and human health. There is still on-going discussion on an appropriate model to adopt for collecting, storage and analysis of data from the Kagera River basin which is under the auspices of the East African Community (EAC).

\section{Discussion}

Similarities in the current disease surveillance structure in animal and human health sectors provide opportunities for

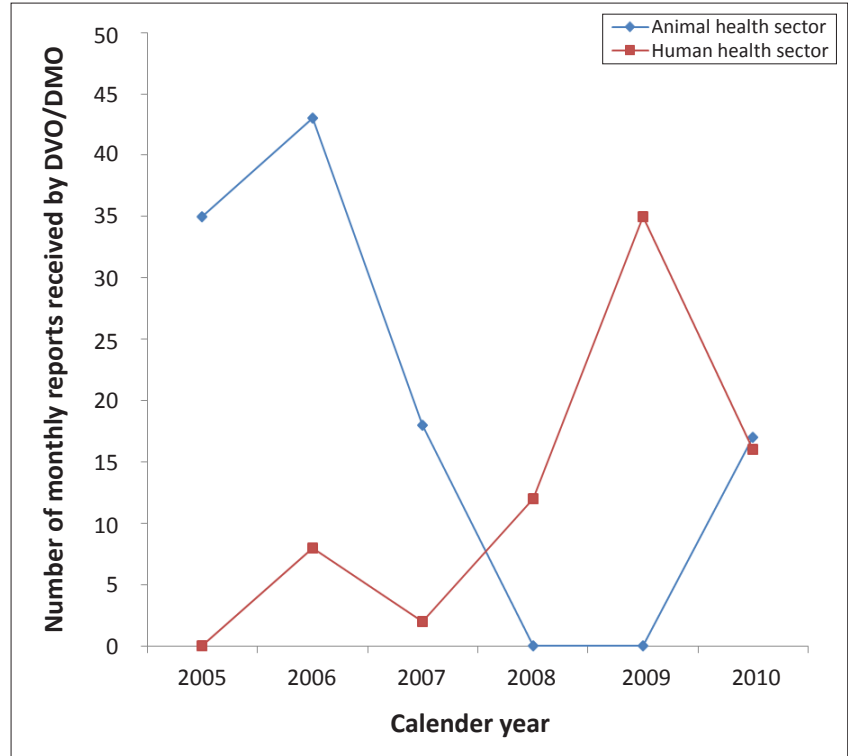

DVO, District Veterinary Office; DMO, District Medical Office.

FIGURE 1: Efficiency of monthly disease reporting in the animal and human health sectors in Ngorongoro district from 2005 to 2010.

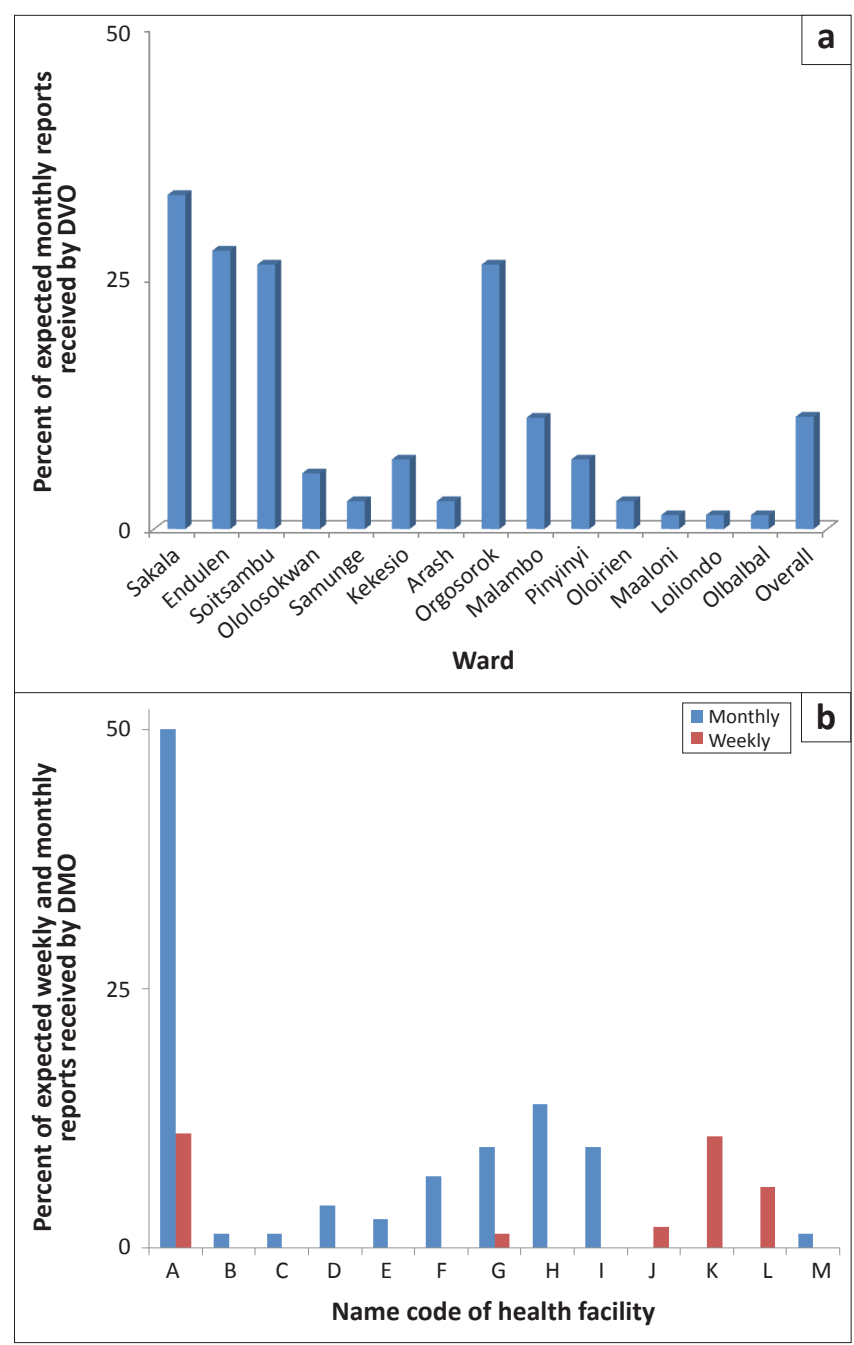

DVO, District Veterinary Office; DMO, District Medical Office.

FIGURE 2: Completeness of disease reporting in the (a) animal and (b) human health sector. 
TABLE 2: Health facilities and wards visited during assessment of surveillance systems in Ngorongoro district.

\begin{tabular}{|c|c|c|c|c|c|}
\hline Name of facility & Category & Owner & Location, ward & $\begin{array}{l}\text { Catchment area } \\
\text { population }\end{array}$ & $\begin{array}{l}\text { Distance to the district } \\
\text { headquarters, } \mathrm{km}\end{array}$ \\
\hline Arash & Dispensary & Faith-based Organisation & Arash & 4291 & 52 \\
\hline Endulen & Hospital & Faith-based Organisation & Endulen & 35168 & 166 \\
\hline Kakesio & Dispensary & District Council & Kakesio & 3945 & 237 \\
\hline Loliondo & Health centre & District Council & Orgosorok & 5569 & 5 \\
\hline Malambo & Health centre & District Council & Malambo & 8816 & 92 \\
\hline Nainokanoka & Dispensary & District Council & Nainokanoka & 29682 & 226 \\
\hline NCAA & Dispensary & Parastatal Organisation & Ngorongoro & 4977 & 178 \\
\hline Ngarasero & Dispensary & District Council & Pinyinyi & 1360 & 122 \\
\hline Oldonyosambu & Dispensary & District Council & Oldonyosambu & 3927 & 93 \\
\hline Sakala & Dispensary & District Council & Sakala & 1455 & 3 \\
\hline Samunge & Dispensary & District Council & Digodigo & 5463 & 65 \\
\hline Sero & Dispensary & District Council & Soitsambu & 2805 & 43 \\
\hline Wasso DDH & Hospital & Faith-based Organisation & Orgosorok & 37345 & 1.5 \\
\hline
\end{tabular}

TABLE 3: Timeline of events that contributed to the development of Southern African Centre for Infectious Disease Surveillance One Health surveillance strategy in southern Africa.

\begin{tabular}{|c|c|c|c|}
\hline Date & Event & Actors $\dagger$ & Achievement \\
\hline January 2010 & $\begin{array}{l}\text { Inception workshop held at Ngurdoto Mountain } \\
\text { Lodge, Arusha Tanzania }\end{array}$ & $\begin{array}{l}\text { Representatives from DRC, Rwanda, Tanzania, } \\
\text { Zambia and UK. Also attended by institutions } \\
\text { involved in surveillance such as InstEDD, } \\
\text { TRACNET Rwanda, P4H, FAO DPT, Imperial } \\
\text { College London-EpiCollect, RVC }\end{array}$ & $\begin{array}{l}\text { Agreed on } 3 \text { pilot sites and technologies to } \\
\text { enhance } \mathrm{OH} \text { surveillance in southern Africa }\end{array}$ \\
\hline July 2010 & $\begin{array}{l}\text { Discussion with EAC Health desk on project } \\
\text { implementation in Kagera river basin }\end{array}$ & $\begin{array}{l}\text { Representatives from SACIDS and EAC- } \\
\text { EAIDSNet }\end{array}$ & Agreed on project coordination arrangements \\
\hline August 2010 & $\begin{array}{l}\text { In-country meeting to discuss project } \\
\text { implementation in Ngorongoro }\end{array}$ & $\begin{array}{l}\text { NatCIDS members from MUHAS, NIMR, SUA, } \\
\text { MoHSW and MoLFD }\end{array}$ & $\begin{array}{l}\text { Appointed a JTC to supervise project } \\
\text { implementation }\end{array}$ \\
\hline September 2010 & JTC meeting & $\begin{array}{l}\text { Members of JTC from SACIDS, SUA, MUHAS, } \\
\text { NIMR, MoHSW and MoLFD }\end{array}$ & $\begin{array}{l}\text { Defined and prioritised diseases and syndromes } \\
\text { to focus on under OH surveillance. Agreed pilo } \\
\text { OH surveillance data to be stored at SACIDS } \\
\text { server on behalf of MoHSW and MoLFD }\end{array}$ \\
\hline September-October 2010 & Visiting UK by SACIDS Postdoc and ICT specialist & $\begin{array}{l}\text { Members from SACIDS, RVC, Imperial College } \\
\text { London and IoE }\end{array}$ & $\begin{array}{l}\text { Received inputs on how to improve } \mathrm{OH} \\
\text { surveillance in Africa and use of technology } \\
\text { (Android phones powered by Epicollect) to } \\
\text { enhance OH surveillance. Hands on practice on } \\
\text { use of the Android phones or Epicollect }\end{array}$ \\
\hline November 2010 & $\begin{array}{l}\text { Setting up data storage system at SACIDS and } \\
\text { field-testing of the Android phones-Epicollect in } \\
\text { Tanzania }\end{array}$ & $\begin{array}{l}\text { Team members from SACIDS and Imperial } \\
\text { College London }\end{array}$ & $\begin{array}{l}\text { Developed local capacity to use Epicollect and } \\
\text { also assessed performance of Android phones- } \\
\text { Epicollect in Ngorongoro }\end{array}$ \\
\hline January-February 2011 & Development of $\mathrm{OH}$ surveillance guidelines & SACIDS team at SUA & $\begin{array}{l}\text { First draft of the surveillance guidelines } \\
\text { developed }\end{array}$ \\
\hline February 2011 & Visiting South-East Asia & $\begin{array}{l}\text { SACIDS team (Postdoc fellow \& ICT specialist) } \\
\text { visited Thailand (BIOPHICS, Epidemiology } \\
\text { Bureau of the Ministry of Public Health \& } \\
\text { MBDS) and Cambodia (InsTEDD) }\end{array}$ & $\begin{array}{l}\text { Learnt on opportunities and challenges with } \\
\text { respect to surveillance and technologies used in } \\
\text { South-East Asia }\end{array}$ \\
\hline March 2011 & $\begin{array}{l}\text { Discussion on project implementation in Zambezi } \\
\text { river basin }\end{array}$ & $\begin{array}{l}\text { SACIDS team and NatCIDS Zambia team at } \\
\text { UNZA Vet }\end{array}$ & $\begin{array}{l}\text { Agreed on project implementation in Zambezi } \\
\text { river basin ecosystem }\end{array}$ \\
\hline March 2011 & JTC meeting & $\begin{array}{l}\text { Members of JTC from SACIDS, SUA, MUHAS, } \\
\text { NIMR, MoHSW and MoLFD }\end{array}$ & Improved $\mathrm{OH}$ surveillance guidelines \\
\hline June 2011 & Exploratory visit, Kagera river basin & SACIDS team and EAC & $\begin{array}{l}\text { Discussed and agreed on how to launch project } \\
\text { activities in Kagera river basin ecosystem }\end{array}$ \\
\hline June-July 2011 & Procurement of Android phones and server & SACIDS \& RVC & $\begin{array}{l}\text { Agreed on procurement plan to initiate } \mathrm{OH} \\
\text { surveillance in southern Africa }\end{array}$ \\
\hline
\end{tabular}

JTC, Joint Technical Committee; EAC, East African Community; SACIDS, Southern African Centre for Infectious Disease Surveillance; ICT, information and communications technology; OH, One Health; DRC, Democratic Republic of the Congo.

$\dagger$, Different institutions from Tanzania (MUHAS, Muhimbili University of Health and Allied Sciences; NIMR, National Institute for Medical Research; MoHSW, Ministry of Health and Social Welfare; MoLFD, Ministry of Livestock and Fisheries Development; SUA, Sokoine University of Agriculture; SACIDS, Southern African Centre for Infectious Disease Surveillance headquartered at SUA and its national chapter, NatCIDS), Zambia (UNZA Vet, University of Zambia Veterinary School), UK (RVC, Royal Veterinary College) and the East African Community (EAC-EAIDSNet, East Africa Integrated Disease Surveillance Network) were involved.

collaboration between the two sectors. For instance, under the current IDSR strategy, emphasis on disease management is placed in hands of district health facility levels (Franco, Setzer \& Banke 2006). Similarly, the MoLFD demands the DVO to be in-charge of managing disease epidemics in animal populations. As both the DMO and DVO work under the umbrella of the District Executive Officer, it is logical to work together in the management of disease epidemics in animal and human populations in their respective districts. This has been happened in some instances during Rift Valley fever and anthrax outbreaks in Ngorongoro district between 2006 and 2009 (B.M. Miran, pers. comm., 2010). It was also found that sometimes animal and human health officials in Ngorongoro district do share vaccine storage facilities during surge demand of resources. This usually happens during disease vaccination campaigns when teams of vaccinators camping in remote areas require storage facilities for proper handling of vaccines. This experience is not new to resourcechallenged remote areas as reported in other countries where sharing resources such as transport logistics and equipment 
reduces costs (Schelling et al. 2007). The current OH strategy designed by SACIDS where one person (community-based health reporter) actively searches for occurrence of disease events is another good example of optimising the use of limited resources.

Findings of the baseline survey agree with previous findings of poor performance of disease surveillance in animal and human health sectors in Tanzania (Allport et al. 2005; Mboera et al. 2001). The situation is made worse with the delayed reporting of sick individuals at health facilities where disease events are normally captured. A study by Shayo et al. (2003) indicated that the majority of rural-based individuals stay at home or consult traditional healers before visiting health facilities to seek medical services. Similar findings have been reported in the animal health sectors where sick animals are usually managed by farmers or community-based animal health workers in remote areas before intervention of veterinarians (Karimuribo \& Swai 2006).

The baseline study also reported a significant variation in completeness of surveillance report in both animal and human health sectors. Although some wards and health facilities seem to do better than others, the overall picture confirms poor surveillance coverage. In-depth interviews of district officials responsible for animal and human health confirmed that the lack of human resources to supervise and manage surveillance systems may seriously affect the performance of the system. This is confirmed, for example, by at the fact that there was no DVO between 2006 and 2009 in Ngorongoro when there was sharp decline in the number of surveillance reports submitted to the district headquarters. This situation was reversed in 2010 after recruiting a veterinarian to head the veterinary section in the district. Other examples were noted where poor reporting was associated with times when key IDSR staff responsible for submitting weekly or monthly reports were away from their work stations. This experience had also been reported previously by Rumisha et al. (2007) when poor disease reporting under IDSR was attributed to staff being on annual leave.

Although quantitative data on timeliness was not collected in the current study, interview with officials responsible for disease surveillance in the animal and human health sectors indicated that there is always delayed reporting, a problem which is more critical in the animal than in the human health sector. For instance, monthly reports in the animal health sector can be delayed by six to nine months before being received by the Epidemiology section (F. Kivaria, pers. comm., 2010). In the human health sector, the timely submission of weekly and monthly reports have been reported to be only $8 \%$ and $24 \%$, respectively (Rumisha et al. 2007). The problem of poor timely reporting is mainly attributed to the paper-based transmission of data coupled with challenging infrastructure and communication networks especially in rural areas.

Given the challenges of surveillance in the animal and human health sectors, the SACIDS designed a 'fit-for-purpose' $\mathrm{OH}$ surveillance strategy. The strategy is considered appropriate for southern Africa as it has taken into consideration the situations and challenges prevailing on the ground. Key considerations include the relatively higher proportion of patients receiving treatment at home from traditional healers before visiting health facilities, lack of proper diagnostic facilities at community and village levels, limited human diagnostic and mobility resources in remote areas as well as poor infrastructure for efficient communication between rural communities and district or ministry headquarters (Strasser 2003). The concept of collaborative efforts in managing infectious diseases in Tanzania and other southern African countries is not new. The emergence of innovative and appropriate technologies, approaches and tools for participatory epidemiology and disease surveillance (Hussain et al. 2005; Jost et al. 2007), such as the use of mobile technologies (Aanensen et al. 2009; Despont-Gros et al. 2005) is likely to mean that infectious disease surveillance can be improved in future. This will contribute to better public health and economic and social stability in Africa. It is also anticipated that the $\mathrm{OH}$ surveillance will foster stronger collaborative links between the animal and human health professionals and consequently improve management and control of infectious diseases in animal and human health sectors.

\section{Conclusion}

The approach designed by SACIDS on $\mathrm{OH}$ surveillance is considered suitable for detecting and containing infectious diseases in animal and human populations in countries with limited resources such as those in southern Africa. Adoption of mobile technologies and appropriate surveillance approaches will improve timely and complete capture of events that would have been otherwise have been missed using routine surveillance systems in the animal and human health sectors. It is concluded that the $\mathrm{OH}$ surveillance strategy is timely and relevant to sub-Saharan Africa.

\section{Acknowledgements}

We would like to acknowledge support and cooperation received from various individuals in the Tanzanian Ministry of Livestock and Fisheries Development, Ministry of Health and Social Welfare, officials at Ngorongoro district council working with the DVO and DMO offices who assisted retrieval of disease surveillance reports. We are grateful to clinical officers, in-charge of different health facilities and wards visited in Ngorongoro district as well as community members who participated in this study. We thank our colleagues at Imperial College London particularly Dr David Aanensen and Mr Chris Powell for their valuable support in capacity building related to setting up, field-testing and use of smartphones running the EpiCollect application in southern Africa. This study was funded by the Rockefeller Foundation through a research support grant 2009 DSN 305.

\section{References}

Aanensen, D.M., Huntley, D.M., Feil, E.J., Al-Own, F. \& Spratt, B.G., 2009, 'EpiCollect: Linking smartphones to web applications for epidemiology, ecology and community data collection', PLOS ONE 4, e6968. http://dx.doi.org/10.1371/ community data collection', PLOS ONE
journal.pone.0006968, PMid:19756138 
Allport, R., Mosha, R., Bahari, M., Swai, E. \& Catley, A., 2005, 'The use of communitybased animal health workers to strengthen disease surveillance systems in

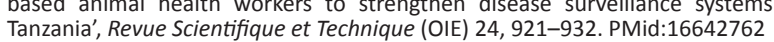

Brownlie, J., Peckham, C., Waage, J., Woolhouse, M., Lyall, C., Meagher, L. et al., 2006, Foresight Infectious diseases: Preparing for the future threats, Office of Science and Innovation, London.

Despont-Gros, C., Boeuf, C., Geissbuhler, A. \& Lovis, C., 2005, 'The Digital Pen and Paper Technology: Implementation and use in an existing clinical information system', Connecting Medical Informatics and Bio-Informatics 116, 328-333.

FAO, 2004, 'Surveillance and zoning for aquatic animal diseases', FAO Fisheries Technical Paper 451, Rome.

Franco, L.M., Setzer, J. \& Banke, K., 2006, 'Improving performance of IDSR at district and facility levels: Experiences in Tanzania and Ghana in making IDSR operational', PHRPlus (unpublished report)

Hussain, M., Malik, M.A., Fatima, Z. \& Yousuf, M.R., 2005, 'Participatory surveillance of livestock diseases in Islamabad capital territory', International Journal of Agriculture and Biology 7, 567-570.

James, J. \& Muchiri, S., 2006, 'HR mapping of the health sector in Kenya: The foundation for effective HR management', Technical Brief (Unpublished report), viewed n.d., from http://www.hlsp.org/LinkClick.aspx?fileticket=eky0oOnoNQA\% 3D\&tabid $=1715 \& \mathrm{mid}=3388$

Jones, B., 2011, 'Analysis of human and animal health system response capacity to epidemic and emerging infectious disease in Tanzania', MSc thesis, Royal Veterinary College, London.

Jones, K.E., Patel, N.G., Levy, M.A., Storeygard, A., Balk, D., Gittleman, J.L. et al., 2008 'Global trend in emerging infectious diseases', Nature 451, 990-993. http:// dx.doi.org/10.1038/nature06536, PMid:18288193

Jost, C.C., Mariner, J.C., Roeder, P.L., Sawitri, E. \& Macgregor-Skinner, G.J., 2007, 'Participatory epidemiology in disease surveillance and research', Revue Scientifique et Technique 26, 537-49. PMid:18293603

Karimuribo, E., Wambura, P., Mounier-Jack, S., Sonoiya, S., Short, N., Aanensen, D. et al., 2011, 'Contrasting features and opportunities for "One Health" infectious disease surveillance system in Tanzania', EcoHealth 7, S49.
Karimuribo, E.D. \& Swai, E., 2006, 'Impact of community-based animal health workers on animal health and extension services: A case study of smallholder dairy farming areas of East and West Usambara, Tanzania', Tanzania Veterinary Journal 23, 57-67.

King, D.A., Peckham, C., Waage, J.K., Brownlie, J. \& Woolhouse, M.E.J., 2006 'Infectious diseases: Preparing for the future', Science 313, 1392-1393. http:// dx.doi.org/10.1126/science.1129134, PMid:16959992

Mboera, L.E.G., Rumisha, S.F. \& Kitua, A., 2001, 'Strategic approach for strengthening national and regional disease surveillance system: The East African example', Tanzania Health Research Bulletin 3, 6-9. http://dx.doi.org/10.4314/thrb.v3i2.14211

Morse, S.S., 1995, 'Factors in the emergence of infectious diseases', Emerging Infectious Diseases 1, 7-15. http://dx.doi.org/10.3201/eid0101.950102, PMid:8903148

Rumisha, S.F., Mboera, L.E.G., Senkoro, K.P., Gueye, D. \& Mmbuji, P.K., 2007 'Monitoring and evaluation of Integrated Disease Surveillance and Response in selected districts in Tanzania', Tanzania Health Research Bulletin 9, 1-11. http:// dx.doi.org/10.4314/thrb.v9i1.14285

Schelling, E., Bechir, M., Ahmed, M.A., Wyss, K., Randolph, T.F. \& Zinsstag, J., 2007, 'Human and animal vaccination delivery to remote nomadic families, Chad', Emerging Infectious Diseases 13, 373-379. http://dx.doi.org/10.3201/ eid1303.060391, PMid:17552089

Shayo, E., Mboera, L.E.G., Mmbuji, P., Rumisha, S.F., Senkoro, K.P. \& Mwami, A.J., 2003, 'The role of community and traditional healers in communicable disease surveillance and management in Babati and Dodoma districts, Tanzania', Tanzania Surveillance and management in B
Health Research Bulletin $5,48-55$.

Strasser, R., 2003, 'Rural health around the world: Challenges and solutions', Family Practice 20, 457-463. http://dx.doi.org/10.1093/fampra/cmg422, PMid:12876121

Thacker, S.B. \& Berkelman, R.L., 1988, 'Public Health surveillance in the United States', Epidemiologic Reviews 10(1), 164-190.

Wickramage, K. \& Nellapalli, P., 2008, 'Community participatory methods in disease surveillance and public health in war-affected camps, and its potential
contribution to peace building', International Electronic Journal of Health Education 11, 95-108.

Wolfe, N.D., Dunavan, C.P. \& Diamond, J., 2007, 'Origins of major human infectious diseases', Nature 447, 279-283. http://dx.doi.org/10.1038/nature05775, PMid:17507975 